NASZA DERMATOLOGIA Online OUR DERMATOLOGY Online

Source of Support: Nil

Competing Interests: None

\section{RELATIONSHIP BETWEEN HEALTH BEHAVIORS AND QUALITY OF LIFE ON THE ONE HAND AND SATISFACTION WITH HEALTH CONDITION ON THE OTHER HAND IN PATIENTS WITH PSORIASIS}

\author{
Mariusz Jaworski \\ Department of Medical Psychology, Medical University of Warsaw, ul. Zwirki i \\ Wigury, Warsaw, Poland
}

Corresponding author: M.Sc. Mariusz Jaworski mjaworski@wum.edu.pl

\begin{abstract}
Introduction: Scientific research suggest that the more severe psoriasis symptoms are the poorer quality of life. Reviews show that appropriate health practices can reduce severity of symptoms of some diseases on the one hand and influence subjective assessment of quality of life on the other hand. The authors tried to assess the frequency of health behaviors in patients with psoriasis compared to the control group, as well as to analyze the relationship between health behavior and the quality of life.

Methods and Methods: The study was conducted on 61 patients with psoriasis and 60 respondents as a control group. Two tools were used in the study: Behavioral Health Inventory and author's questionnaire with questions concerning quality of life, satisfaction with health condition, number of medicines used and severity of psoriasis. Statistical analyzes were performed using Statistica SPPS 18.

Results: Patients with psoriasis assessed as worse their quality of life compared to the control group. In case of intensity of healthy eating habits the similar differences were revealed. Inverse relation was observed in case of prevention behaviors. There were no differences between the groups in terms of positive mental attitude and health practices. Quality of life in patients with psoriasis correlated with a positive mental attitude.
\end{abstract}

Conclusions: Our results suggest the need for comprehensive education in three areas: medical, nutritional and psychosocial.

Key words: quality of life; psoriasis; skin changes; health behaviors

\section{Introduction}

Health behaviors are defined as any behavioral activity undertaken by a person which have an impact on her/his health condition, both positive and negative. The division of these behaviors varies widely in the literature. One reason for this is that one faces many difficulties associated with defining this term depending on the approach [1]. The division based on the relationship 'cause - effect' is most often cited. Accordingly, the behaviors are divided into: favorable behaviors (pro-health behaviors) and unfavorable behaviors (anti-health behaviors) $[2,3]$. The present study analyzes only pro-health behaviors in case of patients with psoriasis. This is due to the fact that in the literature there are no scientific reports that analyze strictly these issues.

Psoriasis is a chronic, genetically determined disease. It is characterized by inflammatory changes of skin with periods of recurrence and remission. Four main factors associated with the pathogenesis of psoriasis are mentioned in the literature, namely auto-immunological, genetic, hormonal and psychosomatic ones [4]. The incidence of psoriasis affects from 1.5 to 3 percent of the population [5] and it is equally frequent in men and women [4].

Diagnosis of psoriasis is associated with the identification of characteristic skin changes in the form of red scaly rashes itching. The treatment of this disease presents one of the most difficult dermatological challenges. The most commonly used treatment methods include: external (specific and non-specific), general (including retinoids, immunomodulating and cytostatic medicines) and physical (including photochemotherapy, phototherapy, heliotherapy) [6].

During recent years scientists have attempted to identify behavioral markers which may directly or indirectly contribute to the severity of skin changes in psoriasis. It is suggested that undertaking activities with positive effect on health while limiting anti-healthy behaviors may reduce the severity of symptoms $[7,8]$. 
This observation is reported in case of various diseases such as cardiac or metabolic diseases [9]. However, there are no publications which would analyze the frequency of health behaviors in patients with psoriasis. Neither there were attempts to analyze the relationship between these behaviors and subjective assessment of quality of life on the one hand, and satisfaction with the current health condition on the other hand. Significant part of publications examine the role of psychological factors in the severity of psoriasis symptoms [10]. The objective of the present research was to assess the frequency of health behaviors in patients with psoriasis compared to the control group, as well as to analyze the relationship between various categories of these behaviors with the level of quality of life on the one hand, and satisfaction with the current health condition on the other hand.

The following research questions were developed in relation to the main objective of present research:

1) Do patients with psoriasis often undertake health behavior compared to the control group?

2) Is there any relationship between the subjective quality of life and health behaviors in patients with psoriasis?

3) Does frequency of health behaviors in patients with psoriasis correlate with their satisfaction with their health condition?

4) Is there any relationship between severity of skin changes in various parts of the body with the subjective assessment of the quality of life on the one hand, and satisfaction with the current health condition on the other hand?

\section{Materials and Methods}

The study was conducted on 61 patients with psoriasis (30 women and 28 men) aged 18 to 67 years. The research was conducted from November 2011 to January 2013. All patients were treated in clinics and hospitals in the region of Mazovia, Poland. Patients were selected using purposive sampling method on the basis of the selection criteria. The subjects were recruited from patients who: 1) were over 18,2 ) had psoriasis diagnosed, 3) were subject to ongoing therapy, 4) and gave informed consent to be part of the study. All patients gave their informed consent.

Control group was included in present research. This group consisted of 60 adults who had not been diagnosed psoriasis. The subjects in this group were recruited from persons who: 1) were over 18, 2) had no psoriasis diagnosed, 3) and gave informed consent to be part of the study. The control group was introduced in order to compare the frequency of health behaviors with regard to patients with psoriasis. Age of the control group ranged from 18 to 66 years.

The gender analysis has not been conducted. This is because the number of men and women participating in the research were inadequate.

Behavioral Health Inventory (BHI) by Z. Juczynski was used in the study. This inventory was designed to examine both healthy and sick subjects. BHI consists of 24 items describing four categories of health-related behaviors. These are: proper eating habits, preventive behavior, positive mental attitude and health practices. BHI is characterized by satisfactory reliability and validity parameters [11].

Proper eating habits assess the frequency of consumption of selected health-related product groups including whole wheat bread, vegetables and fruit. Preventive behaviors facilitate the assessment of the extent to which respondents follow recommendations concerning health, as well as how patients obtain information about health and disease from various sources. Health practices concern the assessment of frequency of eating habits associated with rest, sleep and physical activity. And finally the positive mental attitude makes it possible to characterize behavior aiming at the avoidance of too strong emotions, stresses and strains, as well as of any situation that can lead to depression [11].

Patients assessed the subjective level of quality of life influenced by health in accordance with 5-point scale (1 - very poor, 2 - poor, 3 - neutral, 4 - good, 5-very good). Patients also assessed the subjective level of satisfaction with their health condition using 5 -point scale (1 - highly non-satisfactory, 2 - non-satisfactory, 3 - neutral, 4 - satisfactory, 5 - very satisfactory). In addition, patients were asked to indicate the amount of medicines used, as well as to determine the severity of psoriasis in various parts of the body such as head, trunk, arms and legs with the buttocks. The severity of skin changes on various body parts was assessed using 6-point scale (0 - no change, 1 - to $10 \%$, 2-over $10 \%$ to $30 \%, 3$ - from $30 \%$ to $50 \%, 4$ - over $50 \% 70 \% 5$ - above $70 \%$ to $90 \%, 6$ - more than $90 \%$ to $100 \%$ ). Socio-demographic variables such as age, gender, weight, height were monitored during the research. Body mass index (BMI) was calculated on the basis of the anthropometric data (ie, weight and height) according to WHO guidelines [12].

The data was analyzed statistically using StatSoft Statistica 9.0 software. The $\mathrm{p} \leq 0.05$ criterion of statistical significance was adopted. Since ordinal and interval scale data were analyzed, both parametric and nonparametric statistics were applied. Correlations between variables were analyzed using the Spearman's rank-order coefficient.

\section{Results}

The average age of the analyzed clinical group was 35.13 years $(\mathrm{SD}=14.08)$, while in case of the control group it amounted to 34.92 years $(\mathrm{SD}=11.54)$. There was no statistically significant difference between both groups $(\mathrm{t}=-0.092, \mathrm{p}=$ 0.927). Body weight of persons participating in the research from the clinical group ranged from 51 to $112 \mathrm{~kg}$, while in the control group it fell within the range of 47 to $92 \mathrm{~kg}$. The average body weight was significantly statistically different in case analyzed groups $(\mathrm{t}=-5.314, \mathrm{p}=0.000)$. It amounted to 69.46 $\mathrm{kg}(\mathrm{SD}=12.20)$ for the clinical group and $59.15 \mathrm{~kg}(\mathrm{SD}=8.84)$ for the control group. The average value of body mass index (BMI) was slightly higher in the clinical $(24.16 \mathrm{~kg} / \mathrm{m} 2)$ than in the control group $(21.33 \mathrm{~kg} / \mathrm{m} 2)$ (Tabl. I).

The average level of severity of skin changes did not exceed $30 \%$ in each of the analyzed parts of the body. However, the greatest severity of skin changes was observed in case of head and legs, where changes involved over $90 \%$ in some people. The lowest severity of these changes was observed in case of arms and trunk. These changes did not exceed 10\% (Tabl. II). The average level of subjective quality of life in patients with psoriasis was neutral $(\mathrm{Me}=3.00)$, whereas $14.8 \%(\mathrm{n}=9)$ of respondents indicated that their quality of life was poor. Neutral quality of life was indicated by $36.1 \%(n=22)$ of patients. $49.2 \%(n=30)$ indicated good quality of life. None of the patients indicated that their quality of life was very good or very bad. The level of subjective quality of life was $\operatorname{good}(\mathrm{Me}=4.00)$ in case of the control group. The observed differences were statistically significant $(\mathrm{z}=-5.864, \mathrm{p}=0.000)$.

The average level of satisfaction with the current health condition was neutral $(\mathrm{Me}=3.00)$. 


\begin{tabular}{|c|c|c|c|c|c|c|c|c|c|}
\hline & & \multicolumn{4}{|c|}{ Clinical group } & \multicolumn{4}{|c|}{ Control group } \\
\hline & & Age & Body mass & Growth & BMI & Age & Body mass & Growth & BMI \\
\hline \multicolumn{2}{|l|}{ Mean } & 35,13 & 69,46 & 169,44 & 24,16 & 34,92 & 59,15 & 34,99 & 21,33 \\
\hline \multicolumn{2}{|l|}{ Std. Deviation } & 14,08 & 12,20 & 8,46 & 3,55 & 11,54 & 8,841 & 67,279 & 2,44 \\
\hline \multicolumn{2}{|l|}{ Median } & 33,00 & 68,00 & 168,00 & 23,44 & 33,00 & 57,00 & 168,00 & 20,55 \\
\hline \multicolumn{2}{|l|}{ Minimum } & 18 & 51 & 154 & 17,87 & 18 & 47 & 152 & 18,51 \\
\hline \multicolumn{2}{|l|}{ Maximum } & 67 & 112 & 187 & 32,03 & 66 & 92 & 180 & 31,10 \\
\hline \multirow{2}{*}{$\begin{array}{l}95 \% \text { Confidence } \\
\text { Interval for Mean }\end{array}$} & Lower Bound & 31,52 & 66,33 & 167,28 & 23,25 & 31,93 & 56,87 & 17,61 & 20,70 \\
\hline & Upper Bound & 38,74 & 72,58 & 171,61 & 25,07 & 37,90 & 61,43 & 52,37 & 21,96 \\
\hline
\end{tabular}

Table I. Characteristics of the groups in terms of anthropometric parameters.

\begin{tabular}{|c|c|c|c|c|c|}
\hline & & Head & Arms & Trunk & Legs \\
\hline \multicolumn{2}{|l|}{ Mean } & 2,30 & 0,92 & 1,36 & 1,89 \\
\hline \multicolumn{2}{|l|}{ Std. Deviation } & 1,783 & 1,085 & 1,291 & 1,644 \\
\hline \multicolumn{2}{|l|}{ Median } & 2 & 1 & 1 & 2 \\
\hline \multicolumn{2}{|l|}{ Minimum } & 0 & 0 & 0 & 0 \\
\hline \multicolumn{2}{|l|}{ Maximum } & 6 & 4 & 4 & 6 \\
\hline \multirow{2}{*}{$\begin{array}{l}95 \% \text { Confidence } \\
\text { Interval for Mean }\end{array}$} & Lower Bound & 1,84 & 0,64 & 1,03 & 1,46 \\
\hline & Upper Bound & 2,75 & 1,20 & 1,69 & 2,31 \\
\hline
\end{tabular}

Table II. The severity of skin changes in different parts of the body.

Nobody declared highly satisfactory level. Approx. 11.5\% (n $=7$ ) of patients indicated that they were very dissatisfied with their health condition. Prevailing part of respondents $(37.7 \%, \mathrm{n}$ $=23$ ) indicated their satisfaction with health condition. Neutral appraisal of health condition was showed by $23 \%(\mathrm{n}=14)$ of patients. $27.9 \%(n=17)$ of patients was satisfied with their health condition.

Number of medicines used by participants in the research ranged from 1 to 6 . Average number of medicines used by patients was $2(\mathrm{Me}=2.00)$.

Using Spearman correlation coefficient no significant correlation was revealed between the amount of medicines and subjective quality of life (rho $=-0.110, p=0.200$ ), as well as satisfaction with health $(\mathrm{Rho}=-0.066, \mathrm{p}=0.306)$ in the clinical group. Patients with psoriasis rarely applied health-promoting eating behavior compared to the control group. The observed relationship was statistically significant $(\mathrm{z}=-3.513, \mathrm{p}=0.000)$. The reverse relationship was observed in case of prevention behaviors $(\mathrm{z}=-2.268, \mathrm{p}=0.023)$. There were no statistically significant differences between the analyzed groups in terms of positive mental attitude $(\mathrm{z}=-1.798, \mathrm{p}=0.072)$ as well as health practices $(z=-0.451, p=0.652)$. The detailed description of severity of various health behaviors by participants in the research is presented in Table III.

\begin{tabular}{|l|l|l|l|l|l|l|l|l|l|}
\hline & \multicolumn{4}{|c|}{ Clinical group } & \multicolumn{5}{c|}{ Control group } \\
\cline { 2 - 10 } & $\begin{array}{c}\text { Health-promoting } \\
\text { eating behavior }\end{array}$ & $\begin{array}{c}\text { Prevention } \\
\text { behaviors }\end{array}$ & $\begin{array}{c}\text { Positive mental } \\
\text { attitude }\end{array}$ & $\begin{array}{c}\text { H e a } 1 \mathrm{th} \\
\text { practices }\end{array}$ & $\begin{array}{c}\text { Health-promoting } \\
\text { eating behavior }\end{array}$ & $\begin{array}{c}\text { Prevention } \\
\text { behaviors }\end{array}$ & $\begin{array}{c}\text { Positive mental } \\
\text { attitude }\end{array}$ & $\begin{array}{c}\text { H e a } 1 \mathrm{th} \\
\text { practices }\end{array}$ \\
\hline $\mathrm{X}$ & 19,20 & 21,46 & 19,59 & 18,84 & 22,20 & 19,77 & 20,78 & 18,73 \\
\hline SD & 4,69 & 4,16 & 4,21 & 4,25 & 4,31 & 3,71 & 3,44 & 2,80 \\
\hline M & 20,00 & 21,00 & 20,00 & 18,00 & 23,00 & 19,50 & 21,00 & 18,50 \\
\hline Min & 8 & 13 & 10 & 11 & 12 & 11 & 12 & 12 \\
\hline Max & 30 & 30 & 29 & 28 & 30 & 27 & 27 & 24 \\
\hline
\end{tabular}

Table III. Characteristics of groups in terms of health behavior.

X- Mean / Średnia, SD- Std. Deviation/ Odchylenie standardowe, Min. - Minimum/Minimum, Max- Maximum/ maksimum, M- Median/ Mediana

The severity of all four categories of analyzed health behavior was calculated in this research. It was then compared with different groups of patients. The severity of behavioral categories ratio was calculated according with the guidelines of the BHI author [11]. Our results were compared to research results among patients with diabetes and dialysis patients presented by Juczynski [11].

The comparative summary presented in table 4 is for information only. This is a more complete outline of discussed problem in clinical practice. 
Patients with psoriasis were characterized by lower average values of severity of all analyzed categories of health behavior ratios compared to patients with diabetes. In case of dialysis patients, the differences were recorded for the three health behaviors such as eating habits, preventive behaviors and health practices. The severity of positive mental attitude ratio was slightly higher in patients with psoriasis than in dialysis patients (Tabl. IV).

\begin{tabular}{|c|c|c|c|c|c|c|}
\hline & \multicolumn{2}{|c|}{ Psoriasis } & \multicolumn{2}{|c|}{ Diabetes } & \multicolumn{2}{|c|}{ Dialysis patients } \\
\hline & $\mathrm{X}$ & SD & $\mathrm{X}$ & SD & $\mathrm{X}$ & SD \\
\hline Health-promoting eating behavior & 3,20 & 0,78 & 3,87 & 0,70 & 3,65 & 0,99 \\
\hline Prevention behaviors & 3,58 & 0,69 & 4,00 & 0,63 & 3,67 & 0,80 \\
\hline Positive mental attitude & 3,27 & 0,72 & 3,84 & 0,62 & 3,11 & 0,55 \\
\hline Health practices & 3,14 & 0,72 & 3,70 & 0,75 & 3,47 & 0,82 \\
\hline
\end{tabular}

Table IV. Comparison of health behaviors in patients with psoriasis with other diseases.

Positive mental attitude of patients with psoriasis is characterized by positive relationship with the level of subjective quality of life $(\mathrm{rho}=0.281 ; \mathrm{p}<0.05)$ and satisfaction with health condition (rho $=0.217 ; \mathrm{p}<.05$ ). Results of own research have shown that general level of health behaviors is characterized by a relationship with level of quality of life in clinical group (rho = $0.217, \mathrm{P}<0.05$ ), but there was no relationship with satisfaction with the current health condition. The amount of medicines shows positive relationship with health practices $($ rho $=0.219$,

\section{$\mathrm{p}<0.05$ ) (Tabl. V).}

The study showed positive relationship between severity of skin changes on shoulders with frequency of positive mental attitude $(\mathrm{rho}=0.225 ; \mathrm{p}<.05)$. On the other hand, the severity of skin changes in the area of trunk was positively correlated with health practices ( $r h o=0.217, \mathrm{p}<.05$ ). There was no correlation between the severity of skin changes on head and feet and the frequency of analyzed health-related behaviors (Tabl. VI).

\begin{tabular}{|l|l|r|r|r|r|r|}
\hline \multicolumn{2}{|c|}{} & $\begin{array}{l}\text { Health-promoting } \\
\text { eating behavior }\end{array}$ & $\begin{array}{l}\text { Prevention } \\
\text { behaviors }\end{array}$ & $\begin{array}{l}\text { Positive mental } \\
\text { attitude }\end{array}$ & $\begin{array}{l}\text { Health } \\
\text { practices }\end{array}$ & $\begin{array}{l}\text { The general } \\
\text { health behaviors }\end{array}$ \\
\hline Quality of live & rho &, 102 &, 092 &, 281 &, 204 &, 217 \\
\cline { 2 - 8 } & $\mathrm{p}$ &, 216 &, 239 &, 014 &, 057 &, 046 \\
\hline Satisfaction with health & rho &, 088 &,- 097 &, 217 &,- 078 &, 038 \\
\cline { 2 - 8 } & $\mathrm{p}$ &, 251 &, 229 &, 044 &, 276 &, 384 \\
\hline Number of drugs & rho &, 060 &, 128 &,- 017 &, 219 &, 106 \\
\cline { 2 - 8 } & $\mathrm{p}$ &, 322 &, 164 &, 449 &, 045 &, 209 \\
\hline
\end{tabular}

Table V. Relationship between health behavior and the quality of life on the one hand and satisfaction with health condition on the other hand in patients with psoriasis.

\begin{tabular}{|c|c|c|c|c|c|c|}
\hline & & $\begin{array}{l}\text { Health-promoting } \\
\text { eating behavior }\end{array}$ & $\begin{array}{l}\text { Prevention } \\
\text { behaviors }\end{array}$ & $\begin{array}{l}\text { Positive mental } \\
\text { attitude }\end{array}$ & $\begin{array}{l}\text { Health } \\
\text { practices }\end{array}$ & $\begin{array}{l}\text { The general } \\
\text { health behaviors }\end{array}$ \\
\hline \multirow[t]{2}{*}{ Head } & rho & ,075 &,- 178 &,- 118 &,- 058 &,- 069 \\
\hline & $\mathrm{p}$ & ,282 &, 085 & , 182 &, 330 & 299 \\
\hline \multirow[t]{2}{*}{ Arms } & rho & 086 & ,018 & ,225 & ,128 & 193 \\
\hline & $\mathrm{p}$ & 255 & ,446 & ,041 & ,162 & ,068 \\
\hline \multirow[t]{2}{*}{ Trunk } & rho &,- 171 & ,142 & 037 & ,217 & ,128 \\
\hline & $\mathrm{p}$ & ,094 & ,137 & ,389 & ,047 & ,164 \\
\hline \multirow[t]{2}{*}{ Legs } & rho &,- 121 & ,135 & 137 &,- 109 & 015 \\
\hline & $\mathrm{p}$ & 177, & , 150 & 145 & 201 & ,454 \\
\hline
\end{tabular}

Table VI. Relationships between health behavior and severity of skin changes.

\section{Discussion}

Health behaviors belong to basic factors that facilitate the maintenance of appropriate health condition. This position is confirmed by many scientists who analyze relations between frequency of these behaviors and health condition in the general population and some disease entities $[13,14]$.
This applies in particular to diseases, in case of which significant correlation between lifestyle and severity of symptoms was shown.

Eating habits, which are one of the categories of health behavior have received special attention during recent years. 
The proper diet can reduce the risk of developing certain diseases, especially diet-related ones, as well as can minimize the severity of disease symptoms. This is particularly relevant in case of psoriasis. Preliminary reports suggest that abnormal dietary composition may increase skin changes in psoriasis [15]. According to experts in clinical dietetics and medical nutrition, dietary composition may increase inflammation in psoriasis. It is therefore advisable to combine compatibly proper diet with pharmacotherapy [16]. In addition, nutrients in daily food ration may also affect the functioning of central nervous system, both in terms of functional and structural aspects $[15,16]$. Nevertheless, there are few publications highlighting the importance of science in the field of nutrition in dermatology.

Our results did not confirm the existence of the relationship between the severity of skin changes in psoriasis and healthy eating behaviors. Moreover, the frequency of healthy eating habits for this patients group was significantly lower compared to the control group (i.e., healthy individuals), as well as to certain other diseases. This phenomenon may be explained by the lack of knowledge about impact of diet on the severity of skin changes on the one hand, and lack of obligatory participation of specialists in the field of nutrition, especially clinical dieticians, in complex treatment of psoriasis on the other hand.

Such a view is upheld by the fact that some patients deliberately restrict consumption of certain groups of products, such as dairy products, in their diet. The main factor motivating patients to apply such restrictions is the association between consumption of these products and the intensity of skin changes $[15,16]$. It should be stressed that the patients act in these instances rather intuitively.

The foregoing observations may suggest the need for more nutrition education directed to patients with psoriasis, as well as the need to develop obligatory standards concerning the composition of treatment teams and the role of clinical dietitian in the treatment of psoriasis. The main task of a dietitian in this team would be nutritional education and developing appropriate individualized diet taking into account specific individual needs and comorbidities.

Health-related practices showed positive correlation with the amount of medicines and the severity of skin changes in the area of trunk. There was however no relationship between health practices (e.g. rest, sleep and physical activity) with the level of subjective quality of life and satisfaction with the current health condition.

The results of the research showed positive relationship between positive mental attitude and quality of life on the one hand, and satisfaction with current health condition on the other hand in patients with psoriasis. The more patients with psoriasis showed behavior aimed at avoiding too strong negative emotions, stress and tension the more often they indicated higher quality of life and satisfaction with their health condition.

The observed relationships are consistent with the reports of other researchers who have shown that psychological factors may influence the severity of skin changes in psoriasis [8,9]. The foregoing relationship is especially associated with stressors and ability to cope with stress. If the intensity of stress is greater and patient less able to deal with it, the severity of skin lesions is higher. The very fact of illness is a major source of stress. Additionally, the level of stress is compounded in situations when the disease significantly affects interpersonal relationships (what in fact is occurring in case of psoriasis) [17].

\section{Conclusion}

The results of our research suggest the need to take actions aimed at improving quality of life of patients with psoriasis, as well as the need to conduct education aimed at increasing awareness among these patients on the relationship with their lifestyle and the severity of skin changes in psoriasis, especially in the area of proper nutrition and the ability to cope with the disease itself. The presented results are of preliminary nature and in order to be more reliable, further detailed study with better control of confounders, larger sample, etc. is required.

\section{REFERENCES}

1. Heszen I, Sęk H: Zdrowie i stres, [w:] Psychologia. Podręcznik akademicki. T. 2. Strelau J, DolińskiD (red.), GWP, Gdańsk. 2008; 681-734.

2. Heszen I, Sęk H: Psychologia zdrowia. PWN, Warszawa 2007.

3. Woynarowska-Sołdan M, Węziak-Białowolska D: [Psychometric analysis of Positive Health Behaviours Scale for adults]. Prob Hig Epidemiol. 2012;93:369-76.

4. Christophers E: Psoriasis - epidemiology and clinical spectrum. Clin Exp Dermatol. 2001;26:314-20.

5. Stern RS, Nijsten T, Feldman SR, Margolis DJ, Rolstad T: Psoriasis is common, carries a substantial burden even when not extensive, and is associated with widespread treatment dissatisfaction. J Invest Dermatol Sympos Proceed. 2004;9:136-9.

6. Mease PJ, Menter MA: Quality of life issues in psoriasis and psoriatic arthritis: Outcome measures and therapies from a dermatological perspective. J Am Acad Dermatol. 2006;54:685-704. 7. Davidsson S, Blomqvist K, Molin L, Mørk C, Sigurgeirsson B, Zachariae H, et al: Lifestyle of Nordic people with psoriasis. Int J Dermatol. 2005;44:378-83.

8. Pakran J, Riyaz N, Nandakumar G: Determinants of quality of live in psoriasis patients: a cluster analysis of 50 patients. Indian $\mathrm{J}$ Dermatol. 2011;56:689-93.

9. Vanuzzo D, Pilotto L, Mirolo R, Pirelli S: Cardiovascular risk and cardiometabolic risk: an epidemiological evaluation. G Ital Cardiol (Rome). 2008;9:6S-17S.

10. Hall JM, Cruser D, Podawiltz A, Mummert DI, Jones H, Mummert ME: Psychological Stress and the Cutaneous Immune Response: Roles of the HPA Axis and the Sympathetic Nervous System in Atopic Dermatitis and Psoriasis. Dermatol Res Pract. 2012;403908:1-11.

11. Juczyński Z: Narzędzia pomiaru w promocji i psychologii zdrowia. PTPTP, Warszawa 2001.

12. MacKay NJ: Scaling of human body mass with height: The body mass index revisited. J Biomech. 2010;43:764-6.

13. Winkleby MA, Cubbin C: Changing Patterns in Health Behaviors and Risk Factors Related to Chronic Diseases, 1990-2000. Am J Health Promot. 2004;19: 19-27.

14. Nguyen HT, Markides KS, Winkleby MA: Physician Advice on Exercise and Diet in a U.S. Sample of Obese Mexican-American Adults. Am J Health Promot. 2011;25:402-9.

15. Wolters M: Diet and psoriasis: experimental data and clinical evidence. Br J Dermatol. 2005;153:706-14.

16. Ricketts JR, Rothe MJ, Grant-Kels JM: Nutrition and psoriasis. Clin Dermatol. 2010;28:615-26.

17. Fortune D, Richards H, Griffiths C: Psychologic factors in psoriasis: consequences, mechanisms, and interventions. Dermatol Clin. 2005:23:681-694.

Copyright by Mariusz Jaworski. This is an open access article distributed under the terms of the Creative Commons Attribution License, which permits unrestricted use, distribution, and reproduction in any medium, provided the original author and source are credited. 